\title{
Universidad, dictadura y movimientos estudiantiles en Argentina. Córdoba 1966-19741
}

\author{
María Cristina Vera de Flachs ${ }^{2}$ \\ Universidad Nacional de Córdoba - (Argentina) \\ Grupo de investigación HISULA \\ vera@onenet.com.ar
}

Recepción: 20/04/2013

Evaluación: 15/06/2013

Aceptación: 28/06/2013

Artículo de Reflexión

DOI: http:/ / dx.doi.org/ 10.9757/ Rhela. 21.06

\section{RESUMEN}

El propósito de este artículo es hacer un análisis de la situación de la Universidad Nacional de Córdoba, desde la denominada "Revolución argentina" hasta el fallecimiento de Juan Domingo Perón, centrando nuestra atención en la situación socio política del período el que fue atravesado por movimientos estudiantiles y cambios de normativas para la educación superior que impactaron en la autonomía y en el gobierno universitario.

Palabras claves: Revista Historia de la Educación Latinoamericana, educación superior, políticas de educación superior, Universidad de Córdoba, Argentina, movimientos estudiantiles.

1 El artículo es fruto de un PIP de CONICET titulado: Tradición y modernidad: políticas académicas, ideas, protagonistas, intelectuales y redes de poder. Córdoba - siglos XVIII A XX . Resolución 1207. Código del proyecto: 11220080102879. Se articula al proyecto Reformas y movimientos universitarios en Colombia SGI 1295 desarrollado por el grupo la Ilustración en América Colonial - ILAC y financiado por la Dirección de Investigaciones de la Universidad Pedagógica y Tecnológica de Colombia.

2 Doctora en Historia, Licenciada en Historia por la Facultad de Filosofía y Humanidades, profesora titular de historia social contemporánea de la Universidad Nacional de Córdoba, investigadora del grupo Historia y Prospectiva de la Universidad Latinoamericana, adscrito a la Universidad Pedagógica y Tecnológica de Colombia. 
University, dictatorship and school movements in Argentina. Cordoba 1966-1974

ABSTRACT

The purpose of this article is to analyze the situation of the National University of Cordoba, from the so-called "Argentinian Revolution" until the death of Juan Domingo Perón, Focusing our attention on the socio-political situation of the period which was crossed by student movements and changes in regulations for higher education that have impacted on autonomy and the university government.

Key words: Journal of the history of the Latin American Education, higher education, political of higher education, University of Cordoba, Argentina, student movements.
Universidade, ditadura e movimentos estudantis na Argentina. Córdoba 1966-1974

RESUMO

O propósito deste artigo é fazer uma análise da situação da Universidade Nacional de Córdoba, desde a denominada "Revolução argentina" até o falecimento de Juan Domingo Perón, centrando nossa atenção na situação sóciopolítica do período que foi atravessado por movimentos estudantis e mudanças de normas para a educação superior que impactaram na autonomia e no governo universitário.

Palavras-chave: Revista História da Educação Latino-americana, Educação Superior, Políticas de Educação superior, Universidade de Córdoba, Argentina, Movimentos estudantis.

\section{INTRODUCCIÓN}

Desde casi la fundación misma de la ciudad de Córdoba a hoy, los claustros universitarios han estado unidos a la Historia de la provincia y del país. La Universidad no es una institución más, pues desde sus inicios forja la esencia del cordobés, como sus Iglesias o La Cañada y es por eso que lo que ocurre en ella permite observar la historia desde varias dimensiones: política, económica y social. Todos aspectos muy diferentes donde sin desconocer la diversidad de actores centraremos la atención en los estudiantes que cumplieron un rol particular en el período de estudio en el que el clima socio político no es ajeno a sus preocupaciones.

Hacer la historia de la Universidad de las décadas del sesenta y setenta del siglo XX nos obliga a hacer referencia a un proceso militar: la denominada Revolución Argentina consecuencia del golpe de junio de 1966 y al interregno peronista iniciado con las elecciones de 1973. Concluimos este artículo con el fallecimiento de Juan Domingo Perón en 1974, pues consideramos que los años siguientes fueron difíciles en tanto el gobierno en poder de su viuda dio paso a una frágil democracia que abrió el camino para una oscura y aún más temible dictadura. 
Somos conscientes que estas últimas décadas han posibilitado una evolución de la historiografía sobre la historia de las universidades con nuevos planteos y problemáticas, al permitir una nueva lectura sobre los procesos autoritarios en las altas casas de estudios, no solo de Argentina sino de América Latina. Sin embargo, las investigaciones que hacen referencia al movimiento estudiantil en la Universidad de Córdoba y los cambios de normativas en época de dictadura son bastante recientes. ${ }^{3}$ Nos proponemos en esta investigación analizar el período desde la historia de la universidad la que se ve atravesada por la historia política y social. Con ese objetivo, hemos revisado la documentación de los archivos General Histórico de la Universidad de Córdoba, del Colegio de Monserrat y el General de la Nación, e hicimos algunas entrevistas orales semiestructuradas a miembros de la comunidad que estuvieron involucrados en los conflictos, estas nos permitieron detectar aspectos tales como sentimientos, motivaciones y posiciones adoptadas, aspectos subjetivos presentes en todo relato de memoria. También exploramos las revistas y periódicos de la época y la bibliografía especializada. Por otra parte deseo manifestar que muchas de las situaciones relatadas fueron presenciadas por la autora en tanto en el período estudiado fue alumna y docente de la mencionada Universidad.

\section{Los difíciles años sesenta}

Después de la revolución de 1955 que derrocó el segundo gobierno de Juan Domingo Perón mediante el decreto ley 477/55, el nuevo gobierno derogó la Ley universitaria peronista o 14297 y restableció la ley Avellaneda (1597) de 1885. ${ }^{4}$ Poco después, mediante el decreto-ley 6403/55, se sancionó un nuevo régimen para las universidades, muy detallista en algunos capítulos, pero lo más importante es que les restituyó la autonomía, al ampliar incluso su alcance con respecto al que admitía la ley de 1885; y, por otro lado, por primera vez en la legislación universitaria argentina se prevé la iniciativa privada (art. 28). Si bien dicha norma fue modificada por la Ley 14557 en 1958, es a partir de esa legislación que surgen en el país, luego de fuertes debates y polémicas, las instituciones universitarias privadas.

3 Cf. Las recientes investigaciones editadas en Universidad Nacional de Córdoba, AAVV. Cuatrocientos años de historia, Tomo II (Córdoba: Imprenta de la Universidad, 2013), 9.

4 La ley 1597 fue la primera ley que se dictó para la educación superior en Argentina cuando solo existía la Universidad de Córdoba y la de Buenos Aires. Consulta 7 de junio de 2012 http://www.unlu.edu.ar/ museo/html/documen. Entre los autores que se ocuparon de esta cf. Guillermo Ruiz y Nancy Cardinaux (Comp.), La autonomía universitaria: Definiciones Normativas y Jurisprudenciales en clave histórica y actual (Buenos Aires: Editorial La Ley S.A., 2010), AdrianaPuiggrós, Qué pasó en la educación argentina: desde la conquista hasta el menemismo (Buenos Aires: Kapelusz, 1998). 
La Universidad de Córdoba, primero bajo el gobierno del interventor Dr. Agustín Caeiro y luego del Dr. Jorge A. Núñez, puso en marcha el decreto ley 6403, que fue debatido por el estamento estudiantil reformista. A pesar de los cuestionamientos por los concursos docentes, una vez restaurada la autonomía en 1956 las Universidades argentinas y la de Córdoba en particular iniciaron un período floreciente y un proceso de modernización en sus claustros, favorecido entre otras cosas porque, en esos años se puso en boga la teoría desarrollista que propuso un acelerado crecimiento para superar el atraso en América Latina. En ese contexto, en 1958, la Asamblea Universitaria terminó de redactar los Estatutos y se consolidó la autonomía. ${ }^{5}$ Paralelamente, nace el Consejo Nacional de Investigaciones Científicas y Técnicas como ente autárquico y dependiente de la presidencia de la Nación y luego de la Secretaría de Estado de Ciencia y Tecnología, ${ }^{6}$ el Consejo Interuniversitario, conformado por los rectores de todas las universidades, al tiempo que se aumentó la inversión por parte del Estado en la educación superior lo que permitió transformar las dedicaciones simples de sus docentes en completas.

A partir de entonces, la Universidad de Córdoba se convirtió en un faro científico donde alumbraban congresos científicos, investigaciones de punta que eran publicadas en artículos y libros en el país y en el exterior. En síntesis, docencia e investigación fueron los pilares básicos de la vida universitaria de entonces, aunque no por ello deja de notarse en las Actas del Consejo Superior el permanente reclamo estudiantil por la escasez de presupuestos para una institución que estaba en expansión.

Paralelamente y como consecuencia del surgimiento de la industria automotriz en Córdoba en los años cincuenta se produjo una importante transformación de la estructura socio económica, creció de manera explosiva la población de la ciudad. En el período intercensal de 1947-1960 la provincia pasó de 386828 habitantes, a 577554 y, en 1970, el incrementó continuó hasta alcanzar los 702465 habitantes, aumento que se acompañó con una acelerada urbanización de zonas de la periferia de la capital, particularmente en torno a las empresas terminales ubicadas en la zona sur y un proceso de despobla-

5 Universidad Nacional de Córdoba, Estatutos de la Universidad de Córdoba, 1958 (Córdoba, edición oficial, Imprenta de la Universidad, folleto, 1958), 32.

6 Esta Secretaría pasó a depender del Ministerio de Educación y Justicia y al dividirse este quedó bajo de la dependencia del Ministerio de Educación hasta la creación del Ministerio de Ciencia e Innovación Productiva en el siglo XXI. 
miento de ciertas poblaciones del norte y sur provincial. ${ }^{7}$ A la par que crecía su población, se incrementaba la matrícula universitaria con jóvenes provenientes de distintos puntos del país, de América Latina e incluso de Europa, la que tenía en 196927945 inscritos y en 1970, 33070. Una nota distintiva de la época fue que un alto porcentaje de sus estudiantes trabajaban como empleados $\mathrm{u}$ obreros y el aumento del ingreso de la mujer a los claustros universitarios, la que entre 1961 y 1965 llegó a una matrícula del 33,70\%.8

\section{El clima revolucionario en América Latina: entre la ilusión y el rechazo}

En enero de 1959 tuvo lugar la revolución cubana, que será decisiva para comprender los procesos guerrilleros posteriores en América Latina, región que se militarizó en la década del sesenta. En 1962 Moscú anunció que reforzaría su ayuda económica y militar a Cuba, al instalar en la isla rampas de lanzamiento de cohetes que podían alcanzar Estados Unidos con sus ojivas nucleares. Ambas superpotencias enfrentaron una severa crisis que culminó el 28 de octubre con el retiro de las rampas y de los cohetes por parte de Rusia. Por esos años, Fidel Castro y el PC cubano, dirigidos y apoyados por Moscú, se dedicaron a tratar de exportar su revolución. Sin embargo, al éxito de esta y la de Nicaragua se le oponían los fracasos de la guerrilla en Colombia, Perú, Bolivia, Uruguay y Brasil. De todos modos, el fenómeno guerrillero latinoamericano preocupaba a todos los gobiernos de la región y eso alentaba la necesidad de contar con ejércitos modernos. La idea de la seguridad nacional -el anticomunismo- y en el caso argentino la necesidad de poner en marcha un proyecto nacional que llevase al país a un "destino de grandeza" eran temas cotidianos entre los militares, analistas políticos y medios afines. ${ }^{9}$ En otro orden de cosas, John Kennedy primero y el Concilio Vaticano de 1965, tiempo después, enfatizaron su preocupación por el desarrollo científico de los países pobres, lo que fue recibido en América Latina con profundo entusiasmo por parte de instituciones y también de teólogos y pastores.

7 El Censo Nacional de Población, Hogares y Viviendas de la República Argentina de 1960 estableció que había más de 5000 fábricas instaladas en la ciudad capital.

8 Datos extraídos del Departamento de Estadística, Anuario de Estadísticas Universitarias, Córdoba: UNC, correspondiente al período 1961-1965.

9 Similares conceptos en M. C. Vera de Flachs, "Notas para la Historia de la Universidad argentina, en Revista Historia de la Educación Latinoamericana, No 8 (2006): 65 a 112. 
La Universidad no estuvo ajena a estos acontecimientos y los estudiantes rechazaron el orden existente $y$, lejos de replegarse en los claustros, pasaron a la militancia. A diario los edificios universitarios estaban empapelados con leyendas que daban la pauta de lo que sucedía en América Latina y había amenazas de toma de Facultades con distintos motivos, a la vez que se informaba en la prensa de la existencia de elementos trotskistas y otros grupos de izquierda señalando que dichos grupos no estaban reconocidos por la Universidad. ${ }^{10}$

\section{Las lecturas políticas de los intelectuales cordobeses}

En 1965 falleció en Colombia, en un enfrentamiento con el ejército, el cura guerrillero Camilo Torres y, en octubre de 1967, en Bolivia Ernesto "Che" Guevara. El primero había inspirado los movimientos guerrilleros sociales cristianos y, el segundo, a los grupos de izquierda. Paralelamente Uruguay comenzó a sentir los golpes de los Tupamaros y en Brasil se expandieron otros grupos clandestinos. Los jóvenes latinoamericanos leían La guerra de guerrillas del Che Guevara (1960). La revolución sobre la revolución del francés Regis Debray (quien hoy reivindica a De Gaulle). El Manual del Guerrillero del brasilero Carlos Marighela (1969) y Los Escritos de Mao Tsé-tung. El mismo año el economista colombiano Antonio García escribió La estructura del atraso de América Latina donde concluía:

Que los partidos comunistas centro y sudamericanos por su fidelidad con el régimen alarmaron a las oligarquías capitalistas que temían la instauración de un régimen similar al de Castro, bloquearon el camino exasperando a los jóvenes que buscaron como salida el camino de las guerrillas. ${ }^{11}$

En Córdoba, el espacio cultural se amplió en parte por esas lecturas ya que la producción editorial de fines de esos años sesenta contribuyó de modo decisivo a crear el clima político-intelectual de la nueva izquierda. Libros, fascículos y revistas -donde confluían el neo anarquismo, el surrealismo libertario y el marxismo crítico- fueron la lectura obligada de los intelectuales y de los estudiantes que se movilizaban no solo en esta ciudad

10 En agosto de 1965 el rector Eduardo Cammisa Tecco informó sobre la existencia de estos grupos al Ministro de Educación de la Nación que recabó información al respecto. La Voz del Interior, 5 de agosto, 1965, 10 col.3.

11 Antonio García, La estructura del atraso en América Latina: hacia una teoría latinoamericana del desarrollo (Bogotá: Convenio Andrés Bello, 2006). 
sino también en Corrientes, Rosario, Buenos Aires y Tucumán. ${ }^{12}$ De todas las publicaciones de entonces, destacamos la revista Pasado y Presente que fue dirigida en su primer año de vida por Oscar del Barco y Aníbal Arcondo, quienes en su primer número detallaron los objetivos que esta perseguía, al señalar que aspiraba convertirse en una nueva expresión de la izquierda real argentina y comprometida con todas "las fuerzas que hoy se proponen la transformación revolucionaria de nuestra realidad". ${ }^{13} \mathrm{Su}$ primera época se prolongó entre 1963 y 1965, en nueve números. Ocho años después, la revista reaparecería bajo la dirección de José Aricó, un intelectual gramsciano y secretario de la Federación Juvenil Comunista de Córdoba en sus años de estudiante, que se convirtió en una de las figuras clave de la nueva izquierda argentina y cordobesa en particular junto a Juan Carlos Portantiero. ${ }^{14}$ Pasado y Presente surgió como "expresión de un grupo de intelectuales marxistas" que pretendió continuar con el camino abierto años antes por Contorno, al establecer un puente entre los intelectuales y el proletariado.

Antes del golpe militar de junio de 1966 la Universidad estaba en funcionamiento bajo el ejercicio del cogobierno. El C.S. estaba integrado por los decanos y vicedecanos de las siete Facultades existentes, por dos egresados y cuatro estudiantes, dos por la agrupación Integralismo, uno por Franja Morada y uno por la Federación Universitaria de Córdoba [FUC]. No obstante, de la documentación consultada se desprende que el clima estudiantil era intranquilo y que los jóvenes se proponían reclamar por el incremento de presupuesto y consolidar una alianza obrera-estudiantil. Varios hechos lo demuestran, por ejemplo en abril de ese año, hubo una represión policial en ocasión de realizarse en el Pabellón Argentina una cena del Rotary Club. 300 estudiantes portando estandartes contra esa institución irrumpieron en el lugar, lo que terminó en una golpiza de la policía contra varios adherentes del Integralismo y la detención de dos consiliarios. Se denunció entonces ante el C.S. que la presencia de la policía en la Universidad era permanente, que se sentaban en los bancos y atisbaban en todos los rincones a los efectos de fichar estudiantes. El consiliario estudiantil Alonso señaló que cuando a la CGT le permitieran hacer actos en las instalaciones

12 Horacio Tarcus hizo también referencia a este tema en El marxismo olvidado en la Argentina (Buenos Aires: El Cielo por Asalto, 1996).

13 En su segundo año se sumaron a su Consejo de redacción José Aricó, Samuel Kieczkovsky, Juan Carlos Torre, Héctor Schmucler, César Guiñazú, Carlos Assadourian, Francisco Delich, Luis J. Prieto y Carlos R. Giordano. Raúl Burgos se ocupó del tema en Los Gramscianos Argentinos: Cultura y política en la experiencia de pasado y presente ,Buenos Aires: Siglo XXI, 2004.

14 Su antología del Mayo francés apareció en la colección Cuadernos de Pasado y Presente. 
de la Universidad, él no tendría inconvenientes que lo hiciera el Rotary aun cuando en reiteradas oportunidades esa institución se había manifestado contra el gobierno tripartito y por la intervención de la Universidad ${ }^{15}$. En mayo, el Dr. Silvio Frondizi se proponía disertar en un cursillo organizado por la FUC en la Facultad de Arquitectura sobre "Antecedentes históricos de la crisis económica argentina" pero según denunció el decano de esa casa ante el C.S. cuando estaba por comenzar la charla, un grupo irrumpió "con actitud patotera" por lo que las autoridades y algunos profesores optaron por retirarse, impidiendo así su realización. ${ }^{16}$

\section{La Universidad en el Onganiato}

\section{Política y gobierno universitario}

La denominada "Revolución Argentina" producida el 29 de junio de 1966 derrocó al gobierno del radical Dr. Arturo Illía y posibilitó la llegada al poder del general Juan Carlos Onganía, un militar representante del sector azul del ejército, conservador y ultra católico, que dio por cerrado un período próspero de las universidades nacionales. El 30 de junio, el C.S. de la UNC presidido por el Dr. Tomás de Villafañe Lastra en su carácter de rector en ejercicio por enfermedad del Ing. Eduardo Cammisa Tecco y vista la situación que vivía el país dictó una declaración donde, entre otras cosas, señaló:

\section{[...] que el progreso futuro del país solo podrá lograrse a través de la práctica leal y efectiva de los principios básicos que inspiraron a la or- ganización nacional en lo que atañe al respeto a los derechos y libertades humanos en la observancia de una democracia real como concepción politica y forma de vida. En ese sentido la UNC comprometiendo sus mejores energías para realizar una tarea de afirmación de nuestros valo- res... requiere esencialmente un régimen de autonomía, derivado de la misión que le compete, una libertad académica que permita la aproxima- ción a la verdad a través de la diversidad y aún de la controversia y la participación de todos los integrantes en las tareas y responsabilidades inherentes al cumplimiento de sus fines. ${ }^{17}$}

15 AGHUC, Actas del Consejo Superior, 1966, Tomo I, Fol. 180-183.

16 AGHUC, Actas del Consejo Superior, 1966, Tomo II, Fol. 380. Silvio Frondizi, hermano del presidente Arturo Frondizi, derrocado en 1962, fue uno de los abogados que enfrentó a la dictadura militar argentina entre 1966-1973. En esos años se lo vincula al Partido Revolucionario de los Trabajadores. La Triple A lo asesinó en 1974.

17 AGHUC, Resoluciones del H. Consejo Superior, 1966, Tomo único, Fol. 92. 
Sin embargo, a un mes de esta declaración, la aplicación del decreto ley 16912 se propuso revisar las normas que regían las universidades nacionales con el propósito de eliminar las causas de acción subversiva, anulando el gobierno tripartito y subordinando las autoridades de las universidades nacionales al Ministerio de Educación, prescindiendo del autogobierno y transformando a los Decanos y Rectores en meros interventores. Los Rectores de las Universidades Nacionales de Cuyo, del Nordeste y del Sur aceptaron la disposición. En cambio, los de las Universidades de Tucumán, Córdoba, Litoral, La Plata y Buenos Aires, la rechazaron. En Córdoba el Dr. Villafañe Lastra, a cargo del rectorado, renunció y se designó entonces como interventor de la UNC al Dr. Ernesto Gavier, decano de la Facultad de Derecho. Los interventores nacionales pusieron fin a la autonomía universitaria, disolvieron las agrupaciones estudiantiles, censuraron el debate de ideas y colocaron las casas de estudios bajo la dependencia del Ministerio del Interior. En síntesis, se estableció la autarquía, fortaleciendo la autoridad de rectores y decanos y permitiendo una participación estudiantil limitada. Las comunidades universitarias de todo el país se dieron cuenta de los planes de Onganía, sosteniendo que quería implantar valores nacionalistas y conservadores apoyándose en la Iglesia y en el Ejército.

El 29 de julio, la policía federal irrumpió en la Universidad de Buenos Aires y se produjo lo que se conoció como la Noche de los bastones largos, que implicó el desalojo por la fuerza de docentes y estudiantes que resistían la intervención. ${ }^{18}$ Ese hecho produjo la renuncia y emigración de varios profesores de esa casa de altos estudios. Poco después, en Córdoba, la intensa presión y la falta de libertad en las diferentes unidades académicas trajo como consecuencia el despido de docentes y persecuciones ideológicas, lo que llevó a cientos de profesionales al exilio. ${ }^{19}$

La intervención de la Universidad de Córdoba, en agosto de 1966, y las repercusiones de lo sucedido en Buenos Aires desató una activa movilización estudiantil por las calles de la ciudad y una larga huelga. La politización del estudiantado, sumada a la crisis social, fue una de las preocupaciones mayores del gobierno de Onganía. Gobernaba la provincia el Dr. Miguel Ángel Ferrer Deheza, quien fue reemplazado desde el 8 de setiembre de

18 Gerardo Bra, "La noche de los bastones largos". Todo es Historia 223, (1987): 56.

19 Es larga la lista de profesores cesanteados en Córdoba: 70 solo en la Facultad de Filosofía y Humanidades, pero también se vieron afectados los de la Facultad de Arquitectura, los del IMAF (hoy FAMAF) e incluso varios de la Facultad de Derecho y Ciencias Sociales. 
1967 por Carlos J. Caballero, siendo rector de la UNC el Ing. Rogelio Nores Martínez. En dicho mes, la casa de altos estudios fue clausurada y la huelga reprimida. Diversos grupos estudiantes concentrados en Franja Morada, perteneciente al radicalismo, al Integralismo -una asociación formada en 1955 por cristianos de izquierda y peronistas-, la FUC, Liberación y la Federación de Estudiantes de la Universidad Tecnológica Nacional UTN fueron extendiendo sus reclamos.

Para evitar problemas, el rector clausuró el comedor estudiantil el día 8 de agosto; lo que ocasionó serios inconvenientes, pues el $80 \%$ de los alumnos que a él concurrían provenían de otras provincias, quienes sin dinero para alimentarse comenzaron a regresar a sus hogares. Para evitar la dispersión se decidió instalar "ollas estudiantiles"; la primera se habilitó el sábado 10. La reacción popular fue sorprendente: el gremio de panaderos aportó gratis su producto, alumnos provistos con cajas de zapatos, que intentaban parecer alcancías, detenían los autos solicitando contribuciones y en dos días reunieron $300 \mathrm{mil}$, pesos, mientras otros recaudaban comestibles en las casas de familia. El 22 de agosto hubo una feroz represión callejera de la que no salvaron ni los periodistas que cubrían la información.

\section{El asesinato de Pampillón}

Lo cierto es que las protestas iban en aumento y permanentemente en las calles del centro o en la universidad se realizaban asambleas, en distintos momentos los jóvenes llegaron a ocupar el tradicional Barrio Clínicas, que paso a ser un bastión de las luchas estudiantiles. Una asamblea multitudinaria, realizada en las escalinatas del Pabellón Argentina de la Universidad de Córdoba, definió una huelga por quince días. En la primera semana de setiembre de 1966, miles de volantes convocaron a una asamblea en la Plaza Colón, ubicado en el B. Clínicas, donde moraban cientos de estudiantes en particular los de Medicina, pero el plan falló parcialmente, ya que los jóvenes fueron rodeados por la policía, que apagó el alumbrado público, iluminó la concentración con reflectores y trató de dispersarlos con gases lacrimógenos, obligándolos a saltar como podían el cerco policial y marchar al centro. En la avenida Colón, un policía disparó sobre Santiago Pampillón, un estudiante de segundo año de ingeniería y subdelegado del personal del Departamento de Inspección de la planta de IKA Renault y afiliado al Sindicato SMATA. Esa noche, sus compañeros se concentraron frente al Hospital de Urgencias, 
donde se lo trasladó, replegándose otros en el barrio Clínicas hasta el amanecer. El día 12 sobrevino la muerte de Pampillón, acontecimiento que provocó la reacción inmediata del sindicato y de los estudiantes. La Regional decretó día de duelo a la vez que invitó a concurrir al funeral a la Iglesia del Pilar. ${ }^{20}$ Conocido el hecho, otras universidades nacionales se sumaron a la protesta y organizaron actos de repudio al régimen.

\section{La Política Educativa y el decreto ley 17245}

En abril de 1967 el régimen militar sancionó el decreto ley 17245 (a instrumentarse en 1968) con la intención de dotar a las universidades nacionales de un nuevo ordenamiento jurídico-legal. Se trataba de un proyecto, en el que trabajaron mancomunadamente, estas y el Ministerio de Educación, bien extenso de 125 artículos donde, entre otras cosas, se eliminaban todas las cláusulas relacionadas con el gobierno tripartito, particularmente a lo que se refiere a la integración de los Consejos integrados por profesores, aunque se preveía la presencia de un delegado estudiantil sin voz ni voto. Y si bien el artículo 5 otorgó a las universidades autonomía financiera y autarquía financiera hubo control de las cátedras y se institucionalizó el Consejo de Rectores de las Universidades nacionales como un organismo de representación conjunta frente al Poder Ejecutivo Nacional. ${ }^{21}$

Esta ley fue puesta en práctica en Córdoba durante el rectorado del Ing. Rogelio Nores Martínez quien había asumido en enero de 1967. De carácter restrictivo en lo que se refería a las condiciones de ingreso, permanencia y mantención de la condición de alumno regular, obligando a rendir una materia por año, con excepción de los que hacían el servicio militar, tuvieran una enfermedad grave o un viaje por estudios mayor a seis meses. Los estudiantes latinoamericanos debían aprobar el curso preparatorio sin perjuicio de dar pruebas de equivalencia que se rendían en el Colegio Monserrat, se preveía además el pago de aranceles por el ingreso y por exámenes aplazados y clases obligatorias. A estas disposiciones vino a sumarse a la Resolución 175 del Ministerio del Interior que declaraba disueltas todas las agrupaciones estudiantiles que

20 Mónica Gordillo, "Los prolegómenos del Cordobazo. Los sindicatos líderes de Córdoba dentro de la estructura del poder sindical". Desarrollo Económico, Revista de Ciencias Sociales Vol. 31, 122 (1991):184.

21 Secretaría de Estado de Cultura y Educación de la Nación, Ley Orgánica de las Universidades Nacionales No 17245, promulgada el 21 de abril, 1967 (Buenos Aires: 1967). 
actuaban en la Universidad de Córdoba por considerar que realizaban actividades políticas.

Obviamente este nuevo ordenamiento legal-institucional de la casa de altos estudios provocó la reacción del estudiantado y la oposición de gran parte de la sociedad civil; a lo que se agregó un factor particular de reacción en el seno del estamento estudiantil: que veía con desagrado la presencia de la tradicional oligarquía de la sociedad cordobesa, denominada por Agulla como "aristocracia doctoral" o "aristocracia de toga", en los cargos ejecutivos de la universidad. ${ }^{22}$ Valga como ejemplo significativo que los dos rectores de la Universidad de Córdoba en el período 1966-1969 pertenecían a ese exclusivo y endogámico círculo: el Dr. Ernesto Roque Gavier y el Ing. Rogelio Nores Martínez, ${ }^{23}$ respectivamente.

Con respecto a las universidades privadas en diciembre se sancionó la ley 17604 por la cual se facultaba al gobierno nacional a otorgar contribuciones a quienes las solicitasen. Bajo ese marco se autorizó la creación de 11 casas de altos estudios privadas y 14 nacionales. La aparición de las universidades privadas constituía un hecho nuevo, lo que incentivó a un consiliario a presentar ante el CS de la UNC la necesidad de legislar sobre los antecedentes de los docentes que pretendieran presentarse a concursos en la universidad nacional pues aducía que aquellas discriminaban no solo por el carácter religioso sino también económicos temas que se extendían también a los estudiantes. $^{24}$

Pero mientras estas normativas y acontecimientos políticos producían turbulencias en Córdoba, en Europa, en 1968, desde los centros universitarios de París y Nanterre, se propagaba una rebelión estudiantil que cuestionaba no solo al sistema educativo de ese país, sino también a la "sociedad de consumo", expresión del sistema capitalista al que consideraban injusto. Los estudiantes franceses acompañados por huelgas y manifestaciones sindicales se expresaron en el denominado "Mayo francés". Se iniciaron así una serie

22 Juan Carlos Agulla, Eclipse de una aristocracia. Una investigación sobre las elites dirigentes de la ciudad de Córdoba (Buenos Aires: Ediciones Libera, 1968), 30, citado también por Emilse Pons, "El movimiento estudiantil cordobés durante el onganiato: Una aproximación a las divergencias entre el Reformismo y el Integralismo", consultado el 15 de diciembre de 2012. www.ffyh. unc.edu.ar/archivos/modernidades_a/IX/.../articulo-pons.htm

23 Nores Martínez poseía vasta actuación en los medios políticos y educacionales. Había sido interventor de la provincia de Córdoba durante el gobierno del Dr. José María Guido. Era por ese entonces entre otras cosas copropietario del diario católico "Los Principios" y presidente de la Asociación Cristiana de Dirigentes de Empresas. La Voz del Interior, 2 de febrero, $1967,11$.

24 AGHUC., Actas del Consejo Superior 1966, Tomo 1, Fol. 14. 
de manifestaciones juveniles y obreras que se difundieron a varios países europeos y latinoamericanos y dieron lugar, en algunos sitios, a sangrientas represiones, como la de Tlatelolco en México. No obstante, coincidimos con aquellos autores y entrevistados que opinaron que lo ocurrido en Córdoba en el 69 no tuvo nada que ver con aquellos hechos.

\section{La Iglesia y los curas que dijeron no}

A comienzos de los años sesenta, al igual que lo que sucedía en Europa, sobre todo en España y Francia, se instauró en la Argentina un nuevo fenómeno: el de los curas obreros. El papel de la jerarquía eclesiástica argentina frente al golpe militar de 1966 fue conservador aunque debemos destacar que unos 400 sacerdotes y algunos obispos identificados con los reclamos de los sectores sociales postergados, entre los que se encontraban Enrique Angelelli, de La Rioja; Antonio Brasca, de Rafaela, Santa Fe; Italo Severino Di Stéfano, del Chaco; Jaime De Nevares, de Neuquén. Alberto Devoto de Goya, Jerónimo J. Podestá de la diócesis de Avellaneda y Monseñor Antonio Quarracino entonces vicepresidente del CELAM, lo condenaron por ser una dictadura militar anti popular. Entretanto, el 15 y 16 de octubre de ese año en Unquillo, provincia de Córdoba, se reunieron en el llamado Encuentro Nacional Social Cristiano unos 45 militantes del social cristianismo (conformado por ex demócratas cristianos, nacionalistas, peronistas, sindicalistas, etc.) con el objeto de crear una política adecuada al momento que se vivía ofrecida como partido católico. ${ }^{25}$

El 1 y 2 de mayo de 1968 los sacerdotes enrolados en el Movimiento de Sacerdotes del Tercer Mundo [MSTM] realizaron en Villa Manuela, Córdoba, el Primer Encuentro Nacional del que participaron 21 sacerdotes en representación de 13 diócesis que analizaron la situación vivida en distintas regiones del país y de las villas de emergencia de Buenos Aires y denunciaron los atropellos policiales y ratificaron su opción por los oprimidos. Más de 300 sacerdotes firmaron las propuestas de este encuentro, las que fueron llevadas ante la Conferencia del Episcopado Latinoamericano (CELAM) realizada en Medellín entre el 26 de agosto y el 4 de setiembre de ese año. Entre los

25 Cf. Para el tema entre otros Cristianismo y Revolución, octubre-noviembre de 1966, No 2 (1966): 8 y 9. Claudia Touris, "Sociabilidad e identidad político-religiosa de los grupos católicos tercermundistas en la Argentina (1966-1976)", CD de Jornadas Nacionales de Historia Social (Córdoba, Argentina: La Falda, 2007); Luis Miguel Donatello, "Religión y política: Las redes sociales del catolicismo post-conciliar y los Montoneros, 1966-1973”, Revista Estudios Sociales 24, UNL, (2003), 89-111. De este último autor se puede consultar además su reciente libro Catolicismo y Montoneros: Religión, política y desencanto, (Buenos Aires: Manantial, 2010). 
firmantes había grandes diferencias políticas lo que influyó para el destino final del movimiento.

Al año siguiente el MSTM, que nucleaba a 400 sacerdotes de todo el país, convocó al II Encuentro Nacional el que se realizó, esta vez, en Colonia Caroya, provincia de Córdoba, del 1 al 3 de mayo y en el que participaron 80 sacerdotes de 27 diócesis para reflexionar sobre la "Política y la Pastoral", además de informar sobre la situación socioeconómica de las zonas de dónde venían los participantes. Estos encuentros fueron creciendo en número y reclamos en los años sucesivos. La radicalización ideológica vivida en esa época por la sociedad y dentro de la Iglesia llevó a algunos de aquellos sacerdotes que concurrieron a estas reuniones a tomar las armas junto a grupos guerrilleros o a dejar los hábitos, en tanto otros cayeron víctimas de la violencia de grupos armados de derecha, como la Triple A.

Paralelamente en 1964 los padres Orestes Gaido y Nelson Dellaferrera fueron enviados a la Iglesia Cristo Obrero con la misión de transformarla en una "parroquia universitaria". ${ }^{26}$ El 18 de agosto de 1966, los miembros del Movimiento Integralista cordobés, una agrupación de estudiantes católicos de la UNC nacido después del derrocamiento de Perón, tomaron la Parroquia y realizaron una huelga de hambre en protesta por la intervención universitaria para lo que contaron con la colaboración de los mencionados párrocos. ${ }^{27}$ En un comunicado, el grupo exigió la renuncia del Ministro del Interior, Dr. Enrique Martínez Paz y del rector de la Universidad de Córdoba y pedía que los cargos de rector y decanos fueran cubiertos por profesores "con autenticidad moral y autoridad intelectual", la participación efectiva de los estudiantes en los organismos de gobierno universitario, y la inmediata puesta en marcha de un plan de transformación integral de la Universidad, tendiente a lograr "una universidad identificada con las aspiraciones del pueblo y al servicio de los intereses nacionales". ${ }^{28}$ En octubre los padres O. Gaido y Nelson Dellaferrera recibieron orden del obispo Raúl Primatesta de abandonar la parroquia, momento en el que elaboraron una carta con sus reflexiones explicando por qué su presencia y mensaje molestaba tanto.

26 Lucas Lanusse, "La Universidad Montonera. Agrupaciones Estudiantiles Católicas en Córdoba y Santa Fe y El Origen De Montoneros”. Consultado el 20 de febrero de 2013 rapes.unsl.edu.ar/Congresos_realizados/Congresos/...\%20Oct.../32.htm

27 El equipo estuvo coordinado por Héctor Araujo, Nora LLoveras, Luis Rodeiro, Héctor Bruno y Oscar Correa, Cristianismo y Revolución 2/3, Buenos Aires: octubre y noviembre de 1966, [Medio digital] CEDINCI, 1966.

28 “Cristianismo y Revolución”, Año III, No 18 (primera quincena de julio de1969), [Medio digital] CEDINCI, 1969. 
Después del mayo francés los estudiantes argentinos manifestaron un alto grado de politización, dirigiendo sus reivindicaciones en contra de una enseñanza que consideraban no apta para la necesidad del país, aunque las aspiraciones de algunos grupos minoritarios iban más allá: deseaban ir contra el sistema al punto de pretender cambiar la sociedad en la que vivían. Esta aseveración la confirman las expresiones vertidas en Córdoba, en julio de 1968, por un dirigente estudiantil y obrero de IKA Renault, Máximo Mena, quien señaló:

La lucha por las condiciones y calidades de la enseñanza es muy importante pero, aun así, no es más que un detalle, un escalón de una larga escalera: nuestra lucha, la lucha de todos, en definitiva, es contra el sistema. Hay que convertir cada universidad, cada fábrica y cada barrio en una fortaleza... ¡Compañeros, sigamos el camino del Che Guevara hacia la construcción del socialismo! ${ }^{29}$

\section{Hacia el Cordobazo}

El año 1969 se presentó bastante complicado desde todo punto de vista y en el país los estudiantes debatían en las aulas universitarias los grandes problemas políticos solidarizándose con las clases obreras y enfrentando la dictadura de Onganía. A comienzos de mayo los estudiantes de Córdoba trataron de impedir una reunión de decanos de las Facultades de Medicina de todo el país convocados en esa ciudad con la intención de reorganizar la actividad científica y docente de la especialidad. La protesta se incentivó por la presencia de los decanos de las universidades privadas. ${ }^{30}$ En realidad, durante todo ese mes se produjeron una serie de acontecimientos sindicales y estudiantiles que hacían prever que se estaba frente a las puertas de un conflicto serio.

Desde el rectorado, el Ing. Nores Martínez por medio de mensajes trasmitidos por radio y televisión convocaba al diálogo exhortando a los docentes a que aportaran su experiencia a estos problemas que habían costado vidas de estudiantes. Por intermedio de la Secretaría General de la Universidad dio

29 La Voz del Interior, junio de 1968. La bibliografía sobre el Cordobazo es abundante de dispar valor y no la desconocemos. En tanto no es tema central de este trabajo nos hemos limitado a la información contenida en los periódicos locales y en la siguiente bibliografía: James P. Brennan, El Cordobazo. Las guerras obreras en Córdoba, Buenos Aires: Sudamericana, 1966. Mónica Gordillo, "Los prolegómenos del Cordobazo. Los sindicatos líderes de Córdoba dentro de la estructura del poder sindical" en Desarrollo Económico, Revista de Ciencias Sociales, Vol. 31, 122 (1991), 111-135.

30 AGHUC, Actas del CS., 1969, Tomo 2, Fol. 490. 
un comunicado donde advertía que no había causas específicas para que se haya originado la agitación estudiantil y que para evitar hechos lamentables había decidido suspender las actividades docentes. “Que tanto el rector como los decanos estaban atentos para solucionar las diferentes situaciones que les han planteado los docentes y estudiantes con un elevado criterio de comprensión y ajustado a las normas vigentes". Llamaba a la reflexión de los estudiantes con el fin de proseguir el año académico dentro de un clima de consagración al estudio. Pero en caso que ello no ocurriera las suspensiones de las actividades serían por todo el tiempo necesario. ${ }^{31}$

Multitudinarias asambleas estudiantiles criticaban la actitud del rector sosteniendo que era una táctica para postergar la reacción de los jóvenes, cuya consigna era contra la dictadura y el sistema. Córdoba, como hemos mencionado, presentaba ciertas características que la hacían apta para generar movimientos de protesta, a pesar de tener plena ocupación y los obreros mejor pagos del país. En un ambiente convulsionado obreros y estudiantes operaban coordinadamente y enfrentaban al gobernador, Dr. Carlos José Caballero el que fue reemplazado por el interventor militar Jorge Rafael Carcagno. ${ }^{32}$

El 17 de mayo se conoció en Córdoba la muerte del estudiante chaqueño Juan José Cabral en Rosario y la de Adolfo Roque Bello estudiante de Ciencias Económicas de la Universidad de Corrientes, e inmediatamente se realizó una asamblea en la Facultad de Filosofía y una manifestación por las calles de la ciudad que dejó como saldo tres estudiantes detenidos. El 19 se organizó una Marcha del Silencio que fue rápidamente disuelta por la policía. Estos acontecimientos provocaron la solidaridad de los estudiantes de la Universidad Católica por medio de la Federación de Asociaciones [FAEUCC] de esta universidad en una asamblea donde se fijó la posición solidarizándose con la lucha de los de la Nacional y resolviendo un paro por 48 horas como acto de repudio ante la violencia institucionalizada. Por entonces, buena parte de los dirigentes de las asociaciones por Facultad y el presidente de la FAEUCC eran miembros del AES, Asociación de Estudios Sociales que, casi en su totalidad, fundaron Montoneros, participaron en la toma de La Calera y algunos, luego, se instruyeron militarmente en Cuba.

31 La Voz del Interior, 24 de Mayo, 1969, 20. Periódico de Córdoba. Nota sin autor.

32 Los Principios, 17 de junio, 1969, 9. Periódico de Córdoba. Nota sin autor. 
Entretanto, los jóvenes continuaban de huelga y enfrentamientos con la policía, a la vez que se produjo el cierre de cuatro universidades nacionales, incluida la de Córdoba que "suspendió las actividades para evitar disturbios". Ello explica por qué, el día 28, los jóvenes resolvieron adherir al paro obrero decretado para el día siguiente, que dio como resultado una revuelta conocida como "Cordobazo"33, movimiento que provocará la caída de Juan Carlos Onganía y el fracaso del proyecto militar.

El 29 de mayo amaneció tenso. Aprovechando un paro activo decretado por la Confederación General de los Trabajadores Argentinos [CGTA] algunos sindicatos comenzaron a abandonar las fábricas antes de las 11 horas. La columna de trabajadores de la industria automotriz IKA-Renault iba llegando a la ciudad por una de las arterias principales, la Av. Vélez Sarsfield, pero fueron atacadas por las fuerzas policiales en un intento de dispersarlas. El gobierno dispuso que el transporte urbano de pasajeros abandonara el casco céntrico de la ciudad. Los trabajadores de Luz y Fuerza, los de la Administración Central, los de la Empresa Provincial de Energía Eléctrica [EPEC], pretendieron organizar un acto a la altura de las calles Rioja y General Paz, pero fueron desbandadas con bombas de gases. Una vez más la represión estaba en marcha, prohibiéndose el derecho de reunión, de expresión y de protesta. El comercio del centro cerró sus puertas y las calles se fueron llenando de gente. Entretanto corrió la noticia de la muerte de Máximo Mena del Sindicato de Mecánicos y la de Daniel Castellano, acontecimientos que desataron entre los estudiantes un estallido de bronca contra los atropellos y asesinatos. Los que vivían en Barrio Clínicas construían barricadas y armaban fogatas, ayudados por grupos de chicas que acercaban maderas para atizarlas. Las paredes comenzaron a llenarse de leyendas "Barrio Clínicas, territorio libre de América", "Soldado no tires contra tus hermanos" o "Argentina un país libre de tiranos". De la misma manera, continuaba la resistencia en Barrio Yofre. Los negocios de la calle Colón, una de las arterias más afectada, fueron los que recibieron mayores perjuicios.

Las movilizaciones estudiantiles fueron reprimidas y el caos cobraría proporciones jamás registradas en la historia del país, incluyendo muchos heridos y pérdidas de vida. Con el correr de las horas, la policía retrocedía

33 Francisco J. Delich, Crisis y protesta social, Córdoba 1969 (Córdoba: Fundación de la Universidad de Córdoba, CEA, UNC, 1970), 95-99. 
y nadie controlaba la situación. Ante estos acontecimientos el gobernador Caballero solicitó la intervención de las fuerzas armadas que tardaron varias horas en ingresar en el sector dominado por aquellos. ${ }^{34}$

A partir del Cordobazo, el gobierno nacional creó los Consejos de Guerra Especiales, que rigieron en todo el país, los que decretaron que dentro del radio urbano nadie podía circular por la vía pública entre las 20:30 horas y las 6:30, advirtiendo a la población que las fuerzas de seguridad estaban autorizadas a abrir fuego contra quien lo hiciera en ese lapso. ${ }^{35}$ Pronto, el Consejo de Guerra comenzó a juzgar a centenares de personas, incluidas mujeres y dos dirigentes sindicales: Elpidio Torres y Agustín Tosco a quienes les aplicó ocho años y tres meses de prisión y cuatro años y ocho meses, respectivamente. También dos sacerdotes conocidos por progresistas por su apoyo al clero posconciliar fueron detenidos el día 30, el padre Milán Viscovich, profesor de la Universidad de Córdoba y ex decano de la Facultad de Ciencias Económicas de la Universidad Católica y Erio Vaudagna, párroco de la iglesia de Barrio Los Plátanos, quienes fueron liberados y trasladados al Arzobispado donde quedaron bajo la responsabilidad del arzobispo. Años después, en una entrevista este recordó que en las parroquias de los barrios obreros unos 200 curas tercermundistas trabajaban para construir una Iglesia nueva, pero al no ser comprendidos por la sociedad y presionados por la cúpula de la Iglesia, muchos optaron por renunciar, tal es su caso, que lo hizo en $1972 .{ }^{36}$

El 30 se decretó un paro general en todo el territorio de la República y en los días subsiguientes la ciudad fue recuperando la calma, al reanudarse los servicios que habían sido suprimidos en las jornadas del 29 y 30 . Entretanto, la Universidad mantuvo cerradas sus puertas por siete días, medida que se reiteró en otras oportunidades. Los estudiantes, en acto de protesta, colocaron carteles que señalaban que había sido cerrada por "las minorías burguesas" y que "Nores, el rector, no era el dueño". La Voz del Interior en una nota de reflexión señaló, a su criterio, cuál era la situación que se vivía en ese momento:

34 Los Principios, 29 de mayo, 1969, 9. Periódico de Córdoba. Nota sin autor

35 Para ver las detenciones consultar el periódico La Voz del Interior, 1 de junio, 1969, 19 y 20. Nota sin autor.

36 Entrevista realizada por M. Cristina Mata y Elsa Chanaguir, en Estudios (Córdoba: No 4, CEA). También disponible en www. revistaestudios.unc.edu.ar. 
El país está precipitándose en un abismo de perspectivas inciertas y peligrosas... Haciendo gala de un extraño concepto de autoridad, el gobierno se ubicó en un plano superior y distante de la ciudadanía, siguiendo el impulso de la actitud orgullosa e inexplicable que ha caracterizado a toda su gestión. ${ }^{37}$

No se pueden explicar hoy los hechos de Córdoba sin analizar el papel que cumplió una minoría que encontró terreno apto con el descontento que empezaba a generalizarse contra el Gobierno Nacional que encabezaba el Gral. Juan Carlos Onganía. Los esfuerzos de la izquierda por penetrar en la estructura sindical fueron constantes, habiendo logrado imponer algunos dirigentes como Raimundo Ongaro en el gremio de los gráficos, Atilio Santillán en FOTIA, que reunía a los gremios de la industria azucarera, y a Agustín Tosco en Luz y Fuerza. Debemos añadir que la fractura de la CGT oficial peronista había hecho nacer la llamada CGT de los Argentinos (CGTA) encabezada por Ongaro, que reunía a todas las organizaciones de izquierda.

\section{Después del Cordobazo la toma de La Calera}

El Cordobazo había concluido y entre sus consecuencias se registraron varios muertos, de los cuales una docena eran estudiantes, uno perteneciente a la Universidad Católica que había comenzado a generar un estudiantado deseoso de participar en los cambios que se proponían, ${ }^{38}$ cientos de heridos y de detenidos y una cifra abultada de pérdidas materiales pero lo más significativo es que el acontecimiento hizo mella en el ejecutivo provincial y nacional, al punto que el gobernador de Córdoba debió renunciar.

Desde mediados de 1969 hasta marzo de 1971 la provincia estuvo en manos del Comodoro Roberto Huerta (27 de junio de 1969 a 7 de abril de 1970) y del abogado Bernardo Bas (17 de junio de 1970 al 25 de febrero de 1971), en medio de ambas gestiones hubo otra intervención militar a cargo de Juan Carlos Reyes.

Durante ese lapso las movilizaciones estudiantiles se extendieron a otras regiones del país. En el orden nacional, el 9 de junio de 1970, un año después

$3737 \mathrm{La}$ Voz del Interior el 3 de junio, 1969, 10. Periódico de Córdoba. Nota sin autor.

38 Entre los estudiantes que perdieron la vida había uno de la Universidad Católica, razón por la que en esa institución se decretaron dos días en señal de duelo. Marcela González, Una historia con sentido. Los primeros 50 años de la Universidad Católica de Córdoba, 1956-2006 (Córdoba: Editorial de la UCCC, 2006, 183. 
del Cordobazo, fue depuesto el presidente de facto. ${ }^{39}$ La dictadura militar había quedado herida de muerte; Onganía renunció y fue reemplazado por una "Junta de Comandantes en Jefe" compuesta por el Tte. Gral. Alejandro A. Lanusse, el Almirante Pedro Gnavi y el Brigadier Gral. Carlos A. Rey. Días después, el 13, estos designaron como primer magistrado al Gral. Roberto Marcelo Levingston, quien se desempeñaba como agregado militar y representante del ejército en la Junta Interamericana de Defensa con sede en Washington.

Entretanto, en Córdoba y en el contexto de un reclamo de los trabajadores de IKA Renault y un conflicto estudiantil en las Facultades de Arquitectura, Ciencias Exactas y Derecho, en la mañana del 1 de julio del setenta, un comando de Montoneros tomó por asalto la localidad de La Calera. La elección tenía que ver con la raigambre peronista en tanto este lugar había sido el último foco de resistencia durante la Revolución Libertadora, además de su cercanía con el Regimiento de Infantería Aerotransportada de Córdoba. El operativo duró menos de una hora. Entonces distribuyeron la siguiente proclama:

\begin{abstract}
Compañeros: los hombres y mujeres que componemos Montoneros, brazo armado del movimiento peronista, hemos asestado un golpe a la oligarquía gorila, ocupando militarmente la localidad de La Calera y recuperando armas y dinero, que serán destinados a la lucha para construir una Nación libre, justa y soberana.

[...] El pueblo debe unirse, sin partidismos sectarios, en torno a las banderas intransigentes de la resistencia, buscando prepararse, organizarse, armarse y que sepan los traidores, los vendidos, los torturadores, los enemigos de la clase obrera, que el pueblo ya no recibirá solamente golpes, porque ahora está dispuesto a devolverlos y golpear donde duela. Solo peleando conseguiremos recuperar lo nuestro. Los Montoneros llamamos a la resistencia armada por una patria libre, justa y soberana. Con Perón en la patria. Perón o muerte. ${ }^{40}$
\end{abstract}

Prácticamente todos los integrantes del copamiento pertenecían a la agrupación Montoneros, eran católicos militantes y dirigentes estudiantiles. Después del hecho resultaron detenidos José María Breganti, Felipe Nicolás

39 El 29 de mayo de 1970, día del primer aniversario del Cordobazo, fue secuestrado y posteriormente fusilado el teniente general Pedro Eugenio Aramburu, quien había sido presidente provisional entre 1955 y 1958 y entregado el poder a Arturo Frondizi. Del operativo participaron dos cordobeses: Ignacio Vélez Carrera y Eduardo Maza, enrolados en la línea ideológica de la Revista Cristianismo y Revolución conjuntamente con Mario Firmenich, Norma Arrostito y Fernando Vaca Narvaja.

40 La Voz del Interior, 27 de junio, 2010,10. Periódico de Córdoba. Nota sin autor. 
Defrancesco, Guillermo Martorell Juárez, Juan Carlos Sorati Martínez, Heber Albornoz y José Antonio Fierro. Ignacio Vélez Carreras y su esposa Cristina Liprandi de Vélez. Ignacio, Luis Lozada y Emilio Angel Maza, resultaron heridos, Maza falleció una semana después en el Hospital San Roque. ${ }^{41}$ Los meses de detención los decidieron realizar una autocrítica en lo que se conoce como "Documento Verde" y romper con la conducción de Mario Firmenich y participar en la columna de Sabino Navarro, afín a los curas obreros y a la militancia social. ${ }^{42}$

Entretanto, los detenidos como muchos otros universitarios que compartían esas ideas enarbolaban un discurso donde se cuestionaba el sistema político vigente, regañaban del carácter burgués de la Universidad, a la vez que deseaban acompañar al peronismo y unirse con los trabajadores. Todos los grupos guerrilleros nacidos en la década del setenta estaban compuestos en su mayoría por hombres y mujeres jóvenes, de poco más de 20 años, estudiantes o profesionales de clase media, muchos pertenecientes a opulentas familias tradicionales. El título del diario que se incluye a continuación así lo demuestra.

\section{Imagen 2. Copete del periódico La Voz del Interior de la fecha abajo indicada. Título}

\section{Los Participantes Son Jóvenes de Buena Posición \\ Subsiste todavia en Córdoba la impresión cau- * tos posteriores, se estableció que octuaron uni- sada por el operativo extremista en la pobla- dos elementos de ideologia extremista. Todos ción de La Calera, que estuvo tomada con sus los detenidos son estudiantes, perfenecen a co- por espocio 20 minutos. Se calcula que unos 15 jörenes con 5 automó- de educación. En la requisa de una casa se viles, profusión de armas y aparatos interco- habría comprobado que alli se disfrazó un co- municadores, actuaron en el hecho. La policia che Torino como patrullero policial. En la vi- ha detenido a 6 personas, ya identificadas, en- vienda del matrimonio detenido se hailó un tre ellas un matrimonio; habria otras 6 perso- verdadero arsenal. Otro de los presos llevaba 15 granodas de mano, 4 pistolos aresos llevaba nas más bajo arresto y demoradas otra ćocena 15 granodc en averiguación de los hechos. Por los panfle- 40 revólveres y pistolas, un radiorreceptor y tos y el material secuestrado en los allanamien- 2 uniformes. Pormenores en torno al suceso.}

Fuente: La Voz del Interior, Córdoba, Argentina, 27 de junio de 1970.

41 Maza era dirigente estudiantil del Integralismo cordobés, activista en la lucha contra la dictadura de Onganía, protagonista de la huelga de hambre estudiantil en la Parroquia Universitaria de Cristo Obrero, compartió con monseñor Angelelli y los curas tercermundistas Carlos Fugante, A. Beto Rojas y J. "Pepe" Echevarría, "el intenso debate que atravesaba al cristianismo post conciliar en la búsqueda de un mayor compromiso con los explotados y despojados de la tierra”, Autor, nombre del artículo, Página12, 8 de julio, 2010, Buenos Aires.

42 Guillermo Lehmann "Montoneros golpea en Córdoba”. La Voz del Interior, 27 de junio, 2010. Especial de Guillermo Lehmann. 
A fines de ese año comenzaron los roces entre los generales A. Lanusse y Roberto Levingston, lo que precipitó la caída del gobernador de Córdoba Bernardo Bas, que había logrado mantener buenas relaciones con los gremios, siendo reemplazado por el Dr. José Camilo Uriburu quien tuvo la torpeza de declarar que "tal vez Dios le depararía el honor de cortar la cabeza de la serpiente que anidaba en Córdoba". La respuesta de los cordobeses no tardó en hacerse oír y ante la posibilidad de un nuevo Cordobazo, el Tercer Cuerpo del Ejército volvió a intervenir obligando a Uriburu a renunciar. Su caída arrastraría, el 23 de marzo, la del Gral. Levingston y su reemplazo por A. Lanusse que era el presidente de turno de la Junta de Comandantes, quien terminará aceptando lo que parecía imposible: elecciones libres, esto es, sin la proscripción del peronismo.

\section{El Test de Nores y los estudiantes contra la gestión}

Cabe preguntarnos qué pasaba en este lapso en la Universidad. La presencia del Ing. Rogelio Nores Martínez en el rectorado de la UNC despertó profundo recelo en la mayor parte del estudiantado, en tanto, como hemos señalado, se lo veía como miembro de una elite; así lo manifestó en un comunicado la Federación Universitaria de Córdoba (FUC):

\section{[...] pasará a la página negra de la historia universitaria como ha pasado aquel candidato de la oligarquía para el mismo cargo que se llamó Nores Martínez y que la Reforma Universitaria de1918 repudió... no es casual que en 1967 ocupe el rectorado el ingeniero Rogelio Nores Martínez, in- tegrante de la más rancia oligarquía cordobesa, ex interventor al servi- cio de los monopolistas, defensor de los principios más odiosos a través del diario de su familia, administrador de los bienes escolásticos...". 43}

A fines de 1969 la cuestión estudiantil volvió a cobrar protagonismo cuando una resolución rectoral de Nores Martínez trató de imponer al año siguiente una limitación a las pruebas de ingreso a la Universidad con la obligación de rendir un Test único y común a todas las carreras. La respuesta estudiantil no se hizo esperar aunque las soluciones que se plantearon dejaron al descubierto fracturas entre los grupos. Los ingresantes eran 13000 y el cupo era para 10000, es decir, quedaban de entrada tres mil estudiantes sin posibilidades. Como una manera de paliar la situación, la agrupación estudiantil

43 Comunicado de la Federación Universitaria de Córdoba, La Voz del Interior, 2 de febrero, 1967, 11. 
Franja Morada proyectó el dictado de cursos de preparación para aquellos, sumándose luego otras agrupaciones estudiantiles, en consecuencia, los locales disponibles no daban abasto para los cinco mil estudiantes anotados. Agustín Tosco cedió las instalaciones del gremio Luz y Fuerza para tal fin y allí estuvieron presentes varios curas tercermundistas. En síntesis, los cursos se dividieron en clases teóricas y prácticas. Las primeras se dictaban en las aulas y, las segundas, en la calle. Eso incidió para que los jóvenes ingresantes se iniciaran en la lucha universitaria antes que en el estudio. En las esquinas de Colón y General Paz se difundían las consignas que desde una plataforma, denominada el queso, arengaban F. "Pancho" Delgado, Héctor Silvestro, Simón Gómez, Ernesto, el Caimán, Arocena. ${ }^{44}$

Por su parte, la nueva dirigencia de la FUA en manos del marxista Yaco Tieffemberg impuso medidas de acción directa en contra de dicha resolución, ${ }^{45}$ y la Coordinadora de Agrupaciones de Línea Nacional formada por diversos grupos resolvió resistir todo tipo de restricciones al ingreso libre.

En pocos días, los estudiantes fueron ocupando distintos edificios universitarios, incluido el viejo rectorado en la calle Obispo Trejo y el tema terminó de calentarse cuando se tomó el del Hospital de Clínicas, entre el 30 de enero y el 3 de febrero de 1970. El clima se fue enrareciendo. No obstante, a fines de ese mes se tomaron las pruebas de ingreso presentándose a rendir más del $77 \%$ de jóvenes, ignorando las exhortaciones de quienes querían boicotear los exámenes. Más del $50 \%$ de los ingresantes resultó aplazado y como no podían recuperar, los estudiantes volvieron a reclamar en una marcha hacia las avenidas Colón y General Paz. Entretanto, los padres conformaron una comisión para gestionar cambios, lo que decidió al gobernador Huerta asegurar la equidad de un examen justo y mediar entre el rector y los estudiantes. Ante los nuevos incidentes, se decidió el cierre temporario de la Universidad y, el 29 de marzo de 1970, el Dr. Nores Martínez renunció, y fue reemplazado por el Dr. Olsen Ghirardi. No obstante el cambio de autoridades, las revueltas estudiantiles continuaron, particularmente en la Facultad de Filosofía. Para evitar disturbios, en mayo se realizó una clausura momentánea de la UNC, pero el rector al intentar despegarse de la gestión anterior, dispuso que pudieran rendir nuevamente el test los aplazados y los que no

44 Meses más tarde Arocena y dos compañeros fueron perseguidos por la policía dentro de los claustros universitarios y salvaron su vida gracias a las gestiones de un docente de la Facultad de Derecho, el profesor Ismael Vera, mi padre, a quien rindieron un homenaje en noviembre del año 2011.

45 La Voz del Interior 19 de diciembre, 1969, 12. 
se inscribieron. ${ }^{46}$ En junio el CS resolvió devolver a las facultades la administración del examen de ingreso, para que cada una pudiese tomar sus propias decisiones.

En febrero de 1971 el CS de la UNC, otras universidades nacionales y el Consejo de Rectores resolvieron, en uso de sus facultades, suprimir los cursillos de ingreso para el próximo curso lectivo y transformarlos en cursos introductorios de cada carrera, medida que ocasionó en el sector estudiantil momentos de regocijo aunque las demandas por un ingreso irrestricto continuaron y se hicieron más fuertes a medida que transcurría el año. ${ }^{47}$ En este lapso, la Universidad aceptó un préstamo del BID para construcciones y equipamiento por cuatro millones y medio de dólares y se creó la Caja Compensadora de la Universidad

\section{El Plan Taquini y las universidades privadas}

El médico e investigador Alberto C. Taquini (h) junto con sus colaboradores, los doctores Enrique Urgoiti y Sadi Rifé, ideó un plan para reorganizar las universidades. El tema no era nuevo para él en tanto siendo estudiante universitario realizó una evaluación estadística de la población estudiantil de la Facultad de Medicina de la Universidad de Buenos Aires, a la cual pertenecía. Los resultados dieron cuenta de una "sobredimensión" de la población estudiantil. Impulsado por este dato, en 1967 Taquini y su equipo comenzaron a esbozar lo que luego se denominaría "Plan Taquini", esto es: "la idea del redimensionamiento de nuestra universidad mediante su organización en distintas áreas geográficas donde se operaría la centralización académica, administrativa y la subsiguiente y paulatina organización departamental de la universidad. A su criterio, las nuevas universidades debían estar ubicadas en distintas zonas del país teniendo en cuenta la concentración de la población y el impulso de crecimiento que traería consecuentemente la instalación de nuevas casas de estudio en las diferentes regiones. ${ }^{48} \mathrm{Si}$ bien las nuevas universidades debían estar orientadas hacia zonas de crecimiento vegetativo de la po-

46 AGHUC., Resoluciones Rectorales, 1970, No 240. La Voz del Interior 29 de marzo, 1970, 22.

47 Pablo Bonavena, y Mariano Millán, "La lucha del movimiento estudiantil cordobés por el ingreso irrestricto a la Universidad en 1970 y 1971”. En Estudios de la historia de Córdoba en el siglo XX. Tomo II., Gardenia Vidal, y Jessica Blanco, 65-84. (Córdoba: Ferreyra edit, 2010).

48 Mariana Mendonça, Políticas de estado, segregación espacial, y creación de universidades nacionales en los años setenta. El caso de la Universidad Nacional de Río Cuarto. Consultado 8 de setiembre de 2012 www.mov-estudiantil.com.ar/terceras/2siete.doc. 
blación, se procuraría profundizar una tendencia a la descentralización. En 1969, se reglamentaron las disposiciones de la ley17604 sobre las universidades privadas y el 29 de noviembre por ley 17987 el poder ejecutivo creó la décima universidad argentina: la Universidad Nacional de Rosario, teniendo en cuenta que el $73 \%$ de los alumnos inscritos en la Universidad Nacional del Litoral y un alto porcentaje de sus docentes correspondían a la mencionada ciudad.

Durante el gobierno del general A. Lanusse (1971-1973) se dispuso una descentralización de las universidades nacionales de acuerdo con el plan antes mencionado, llegaron a crearse 5 universidades privadas y 13 nacionales en distintas provincias. La primera erigida en la provincia de Córdoba fue la Universidad de Río Cuarto en 1971. Este plan fue criticado por los estudiantes que suponían que los militares las fundaban con la idea de descentralizar las grandes universidades nacionales, dispersar al estudiantado, evitar la politización y las posibles protestas. ${ }^{49}$

Obviamente hubo cambio de rectores y la intención de realizar modificaciones en la educación superior. Sin embargo, los gobiernos que siguieron no pudieron evitar el grado de politización instalado en los claustros universitarios. Fueron años difíciles y las aulas serán fiel reflejo de lo que acontecía en el país.

El reemplazo de Juan Carlos Onganía y la designación de un interventor en la provincia, Bernardo Bas no modificaron ni el discurso ni los conflictos del sector estudiantil y obrero. El mismo gobernador en declaraciones a la prensa manifestó que la situación socio política de la provincia era complicada en tanto un $5 \%$ de la población revistaba como estudiante y otro tanto trabajaban en los complejos industriales asentados en los alrededores de la ciudad. Sumado a ello, en ese tiempo varios grupos pequeños, al decir de Bas, creían en la violencia como método de cambio. Por ejemplo, la organización Montoneros clamaba por el retorno de Perón entendiendo que con su presencia se abriría el camino hacia el socialismo en la Argentina.

49 María Mercedes Civarolo de Gutiérrez, Plan Taquini. Análisis, crítica y perspectivas (Tesis Licenciatura en Ciencias de la Educación, Universidad Católica de Córdoba., 1986. (Inédito), [Microfichas]. Consultado 9 de setiembre de 2012. www.ucc. edu.ar/biblioteca/biblioteca_trejo.php?sec $=3 \& 591$ 
Pero poco pudo hacer el gobernador, pues su gestión concluiría en febrero de 1971 en medio de una serie de conflictos laborales, fue reemplazado por José Camilo Uriburu, de quien hicimos referencia señalando la necesidad de luchar contra la subversión La respuesta de los cordobeses fue terrible y ante la posibilidad de un nuevo Cordobazo el Tercer Cuerpo del Ejército volvió a intervenir obligando a Uriburu a renunciar. Su caída arrastraría, el 23 de marzo, la de Levingston y su reemplazo por Lanusse que, era el presidente de turno de la Junta de Comandantes, quien inició la marcha de una apertura y de diálogo con el peronismo.

\section{La matanza de Trelew}

El 22 de agosto de 1972 se produjo lo que se conoce como la matanza de Trelew cuando 16 jóvenes, miembros de distintas organizaciones armadas peronistas y de izquierda, presos por causas políticas en el penal de Rawson -ubicado al sur del país- fueron ultimados en un intento de fuga, hecho que desencadenó un movimiento de protesta en el país y en Córdoba, en particular. La CGT de esta ciudad ofreció su sede para el velatorio de los jóvenes cordobeses que perdieron la vida en aquellos hechos y decretó un paro como señal de protesta y algunos sacerdotes celebraron misa en solidaridad con las víctimas. El III Cuerpo del Ejército acusó a la CGT de hacer una encendida apología del delito..$^{50}$

Frente a este hecho, la reacción estudiantil no se hizo esperar en todo el país. En Córdoba, concretamente el 22 de ese mes, se realizó una asamblea estudiantil en la Facultad de Arquitectura, donde se colocó una bandera del ERP con un crespón negro, pero pronto la reunión fue interrumpida por camiones y por la brigada anti explosivos que detuvo a 674 estudiantes. El interventor de la Facultad, arquitecto Soria, denunció violencia en el operativo policial a la vez que un grupo de docentes hizo responsables a las autoridades policiales por la integridad física de los jóvenes.

Por su parte, los de Medicina ocuparon el Hospital de Clínicas luego de una numerosa asamblea impulsada por el Movimiento de Unidad Reformista y del Centro de Estudiantes de Medicina, a los que se unieron médicos re-

50 Mayores detalles en Francisco Urondo, Trelew. La patria fusilada, Buenos Aires, Editorial Contrapunto, 1988; Pablo Augusto Bonavena, "El movimiento estudiantil frente a la masacre en Trelew del 22 de agosto de 1972", Conflicto Social, Año 4, No 5, (2011): consultado en red en febrero de 2013. http://webiigg.sociales.uba.ar/conflictosocial/revista 
sidentes y externos y poco después tomaron simbólicamente el Comedor Universitario, realizando una conferencia de prensa. Finalizada la toma, los estudiantes se dirigieron hasta la planta de Ika Renault (en Santa Isabel) para solicitar la solidaridad obrera. ${ }^{51}$ Un grupo de trabajadores se sumó a los estudiantes y marcharon hasta la sede de Luz y Fuerza, donde se realizaba una reunión de docentes que estaban en conflicto, a quienes les expresaron su apoyo.

\section{El interregno Peronista}

\section{De Cámpora a Perón}

Uno de los últimos actos del ciclo de la Revolución Argentina en la Universidad de Córdoba fue la aprobación de una resolución rectoral que comunicaba el otorgamiento del Doctorado Honoris Causa al cardenal Raúl Francisco Primatesta, que fue otorgado el 15 de mayo de 1973. En el discurso de agradecimiento el cardenal reconoció que la distinción objeto era "el reconocimiento a la tarea cultural de la Iglesia, del influjo de la Iglesia en el mundo de la cultura, aquí, en esta ciudad". Es decir, para él la vida cultural de Córdoba estaba atada a la Iglesia y desde esa visión la Universidad para él tenía una sola misión, la religiosa. ${ }^{52}$

Para entonces ya se había convocado a elecciones. El 15 de abril en segunda vuelta triunfó con el 54\% de los votos el peronismo, después de 18 años de proscripciones con la fórmula del FREJULI conformada por el Dr. Héctor Cámpora y Vicente Solano Lima, en el orden nacional, y Ricardo Obregón Cano-Atilio López, en el provincial, iniciaron los respectivos gobiernos el 25 de mayo. ${ }^{53}$ Fue el momento de mayor gravitación en la provincia del poder de un grupo de tendencia revolucionaria que venía movilizándose y luchando desde antes del Cordobazo y esto alcanzará a las universidades estatales con el nombramiento de rectores adictos a la juventud peronista.

A pocos días de asumir, el 29 de mayo, se dispuso la intervención a las universidades nacionales con el objeto de "ponerlas al servicio del pueblo" en el marco del proyecto de liberación nacional y su revisión de objetivos,

51 Similares conceptos en Bonavena Pablo, "El movimiento estudiantil”, 188.

52 Los Principios, 16 de mayo de 1973.

53 Mayores datos sobre este gobierno en el libro de Luis Baronetto, L., Rodeiro, G., Vazquez, Córdoba 1973. Escritos para Ricardo Obregón Cano (Córdoba: Edit. Facultad de Filosofía y Humanidades, 2012). 
contenidos y fines de enseñanza. En Córdoba, el Dr. Próspero Francisco Luperi ocupó el Rectorado desde el 4 de junio de 1973 como interventor, y los decanatos se repartieron casi por mitades entre las corrientes afines a la izquierda peronista y los sectores ortodoxos. ${ }^{54} \mathrm{El}$ resultado fue una matriz heterogénea que impidió realizar transformaciones significativas.

Las autoridades que asumieron la conducción de las universidades en aquellos tumultuosos días de mayo de 1973, y que eran afines a las organizaciones más combativas del peronismo, decretaron entre otras medidas la expulsión de docentes y funcionarios identificados con el régimen militar iniciado en 1966 y aquellos que trabajaban en empresas multinacionales. Durante esos meses se trató de implementar un proceso de cambio en las estructuras curriculares y administrativas. Se modificaron los contenidos de la enseñanza en varias carreras y las formas de evaluación. Hubo designación de docentes interinos relacionados con las concepciones políticas del grupo que se hizo cargo de las casas de estudios. El 6 de junio se rescindió el nombramiento del profesor Adelmo Montenegro como director de la Escuela de Ciencias de la Información, se suspendieron los concursos en trámites y se reincorporaron los profesores titulares, adjuntos y auxiliares dejados cesantes en el golpe contra Perón de 1955. ${ }^{55}$ Se creó la Editorial Universitaria y el Centro Interdisciplinario del Federalismo bajo dependencia directa del rector, con un director que duraría tres años en sus funciones.

Los interventores de todas las universidades nacionales incluyendo al de la UNC presentaron ante el ministro de Educación y Cultura de la Nación Dr. Jorge Taiana, sus renuncias. El Dr. Luperi lo hizo el 18 de mayo en los siguientes términos:

De mi mayor consideración, con motivo de haber sido sancionada la nueva ley universitaria cumplo en hacer llegar a usted mi renuncia al cargo de interventor en la Universidad Nacional de Córdoba con el que fuera honrado oportunamente por el superior gobierno de la Nación. Hago propicia esta circunstancia para agradecer todo el apoyo que usted prestó a esta alta casa de estudios y las consideraciones personales que particularmente me dispensó. Sin más reciba mi consideración más atenta y amistosa. ${ }^{56}$

54 Decreto 64/73 del Superior Gobierno de la Nación en A.G.H.U.C., Intervenciones nacionales, 1973, Resolución No 1.

55 La Escuela de Ciencias de la Información fue creada por la ordenanza 52/71 del CS. De la UNC, siendo su primer director el prof. Adelmo Montenegro.

56 Noticias sin autor. La Voz del Interior y Los Principios, 20 de mayo, 1974. 
En el ámbito nacional, y a menos de dos meses de iniciar sus mandatos, el 13 de julio, Cámpora y Solano Lima renunciaron a sus cargos, siendo reemplazados por el presidente de la Cámara de Diputados y yerno de López Rega, Raúl Lastiri, quien convocó a elecciones para el 23 de setiembre de las que resultó triunfante, por amplio margen, la fórmula encabezada por Juan Domingo Perón y su esposa María Estela Martínez de Perón.

Entretanto en Córdoba, el 27 de febrero de 1974, el Jefe de Policía Teniente Coronel (Re) Antonio Domingo Navarro, iniciador de los primeros grupos parapoliciales de la ciudad, inició una sedición policial que pondría fin al tercer gobierno peronista encabezado por Obregón Cano y Atilio López. Después vendría la designación transitoria de Mario Dante Agodino, presidente de la Cámara de Diputados y, luego la de Duilio Brunello, la del brigadier Raúl Lacabanne y Raúl Bercovich Rodríguez. En consecuencia, la universidad sufrió el embate de la derecha peronista y todo fue un caos. Lacabanne al asumir explicó su filosofía de gobierno "para que haya libertad debe haber orden y autoridad" y esta lógica la trasladaría a la Universidad. La persona postulada para reemplazar a Luperi en el cargo de Rector de la UNC fue el Dr. Mario Víctor Menso, médico del Hospital de Clínicas. ${ }^{57}$

\section{La cultura de la violencia y las organizaciones terroristas}

A fines de la década del sesenta, el mundo entero vivió una serie de acontecimientos que hacían presagiar cambios vertiginosos, que no tardaron en repercutir en las universidades argentinas: la oposición de los jóvenes a la guerra de Vietnam, el Mayo Francés, la militancia de los sacerdotes tercermundistas y figuras de la talla del Che Guevara y Camilo Cienfuegos fueron despertando en algunos grupos universitarios un compromiso político más profundo que en épocas anteriores. Bregando por un nuevo orden, proclamaban por aquellos días la consigna La patria socialista, ni yanquis ni marxistas.

Sus críticas, rebeldía y rechazos a la sociedad de sus mayores, sus discursos con un alto grado de politización y los debates progresivos en la Universidad iban en contra de la institución a la que tildaban de conservadora y a la que deseaban cambiar. Reclamaban una enseñanza apta para las necesidades del país, sin embargo, las aspiraciones de un grupo

57 Decreto 1807, en el Boletín Oficial de la República Argentina No. 23.056. 
más pequeño iban contra el sistema, por tal razón consideraban necesario modificar la realidad y modelar un "hombre nuevo" que cambiara el rumbo de las cosas: la dependencia económica, la injusticia social y la proscripción del peronismo.

Esta perspectiva alentó las primeras experiencias guerrilleras en Argentina, las que se desarrollaron alentadas por el fervor que se vivía en toda América Latina. Entre los numerosos grupos y células terroristas surgidas entonces, había cinco importantes: Las Fuerzas Armadas Revolucionarias (FAR), las Fuerzas Armadas Peronistas (FAP), y las Fuerzas Armadas de Liberación (FAL), Montoneros. Por su parte, Mario Santucho había formado en 1970 el P.R.T., organización que serviría como base para el lanzamiento del Ejército Revolucionario del pueblo (ERP), el grupo guerrillero más organizado y radicalizado conjuntamente con las FAR que vio Argentina. La existencia y accionar de estos grupos expresaron ideologías diferentes, aunque frente a la represión, Montoneros y ERP, después de la muerte de Juan Domingo Perón, terminaron por cooperar entre sí.

\section{Imagen 1. Tapa de la Revista Cristianismo y Revolución con las siglas de los grupos guerrilleros de la década}

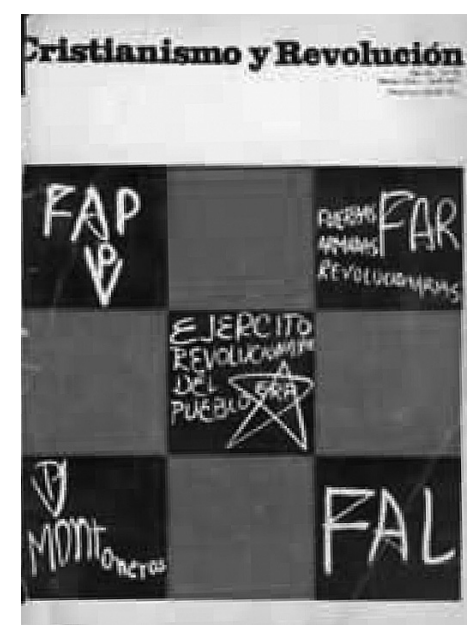

Fuente: tapa de la Revista Cristianismo y revolución Ano IV, N. 28 de abril de 1971.Buenos Aires, Director Juan Elorrio

A la violencia se respondió con violencia, lo que impedía el normal funcionamiento del país. Durante los años subsiguientes, la subversión mantuvo e intensificó sus ataques, que fueron reprimidos por las fuerzas armadas, al 
tiempo que el cuerpo social en general estaba atemorizado ante, lo que se reflejaba en la opinión pública, una guerra abierta entre grupos facciosos y el ejército.

En los setenta Córdoba se vio afectada por este proceso y los estudiantes en aulas y pasillos universitarios cantaban "luche, luche, luche y no deje de luchar, por un gobierno obrero y popular". Un rasgo para destacar fue la unión de los estudiantes de la Universidad Nacional con los de la Católica y la solidaridad con los sindicatos que nucleaban a los obreros de FIAT, SITRAC-SITRAM y los de la planta de IKA Renault.

Paralelamente, una interminable ola de atentados y asesinatos agobiaba a la población pero, a la vez, comenzaron a circular denuncias sobre torturas policiales a los detenidos por cuestiones políticas y violaciones a los derechos humanos.

Los estudiantes concentraron su resistencia en dos grupos escindidos de la proscripta FUC: el Frente Estudiantil Nacional (FEN) que había extendido su influencia en Córdoba después de 1969 y la Coordinadora Estudiantil en lucha de orientación marxista. La prensa de la época hizo constar que, en 1974, hubo 900 víctimas fatales y centenares de personas detenidas. La lucha contra el gobierno de Lacabanne fue cruenta y la pelea se dirimía entre el peronismo de derecha y de izquierda, y por quién hegemonizaba el peronismo. Según lo explicó el propio Santucho en su folleto "Poder burgués, poder revolucionario"' las fuerzas revolucionarias se iban preparando para dar la batalla final por el poder y desplazar al interventor "un fascista hecho y derecho", cuyo sostén era la policía.$^{58}$ Hubo muertos de ambos bandos y atentados con diferentes objetivos.

En síntesis Córdoba mostraba en ese año 74 un panorama bastante convulsionado y una escalada de violencia. J. D. Perón ya en el poder, tratando de poner fin a ese ambiente, pronunció varios discursos desde la Residencia Presidencial en Olivos, allí recibió a la Confederación General del Trabajo [CGT cordobesa] y a la juventud peronista y refiriéndose a la provincia dijo:

58 Mario Roberto Santucho, estudiante en la Universidad de Tucumán, fue fundador del Partido revolucionario de los trabajadores (PRT) y comandante de la mayor guerrilla marxista (no peronista) de Argentina, el ejército revolucionario del pueblo (ERP). Murió en un enfrentamiento con un grupo de tareas del Ejército Argentino en Villa Martelli (provincia de Buenos Aires) el 19 de julio de 1976. 
Sé que Córdoba es una provincia que no es fácil; sé que es una provincia con gran predicamento sindical y gremial, pero no debe olvidar que eso nos lo debe a nosotros. Cuando llegamos al Gobierno, en Córdoba no había más que doctores. Ahora hay trabajadores. Fuimos nosotros los que descentralizando la industria llevamos un gran factor industrial a Córdoba. Esa provincia no nos pagará sino con muchos años de agradecimiento lo que hemos hecho con ella. La hemos transformado en un gran centro industrial y esa es obra exclusivamente nuestra. Fue el Justicialismo el que se acordó de que, al descentralizar la industria, teníamos que darle a Córdoba un coeficiente suficiente como el que tiene actualmente. ${ }^{59}$

Al igual que a los gremialistas, poco después Perón le reiteró a la juventud peronista la necesidad de unificación de los distintos grupos para evitar la infiltración extremista pues "nosotros luchamos por una patria justicialista".

\title{
13. Perón y la ley universitaria 20645
}

En mayo de 1973 cuando asumió la presidencia de la Nación, Juan Domingo Perón designó como Ministro de Educación a Jorge Alberto Taiana. Durante el lapso de dicha gestión, se promulgó la ley de universidades nacionales (20645) que venía a derogar la 17245 y que en su primer artículo manifestaba la voluntad de vincular estrechamente la educación universitaria con el proyecto político del gobierno. Taiana, al presentar el proyecto ante el Congreso de la Nación, el 12 de febrero de 1974, hizo un diagnóstico de la situación de las universidades nacionales en los siguientes términos:

\begin{abstract}
A nadie escapa la trascendencia de la educación superior en el proceso de unidad, reconstrucción y liberación nacional emprendido por el Gobierno popular. Es conocida igualmente la situación conflictiva de las casas de altos estudios: la vigencia de una legislación inapropiada y restrictiva, la carencia de participación en el gobierno de esas instituciones por parte de los diversos claustros que componen la comunidad universitaria: la falta de interrelación con el medio: $y$, finalmente, la inadecuada orientación y la obsolescencia de las estructuras y métodos del sistema de educación superior, en relación con los requerimientos políticos, culturales, sociales y económicos de la hora. ${ }^{60}$
\end{abstract}

\footnotetext{
59 Presidencia de la Nación, Discurso de Perón desde la residencia de Olivos a los gremialistas cordobeses y a los jóvenes (Buenos Aires: Impreso en los Talleres Gráficos de la Dirección Nacional del Registro Oficial, 1974).

60 Ley 20654/74.http://www.coneau.gov.ar/archivos/547.pdf. Consultado: 28 de Febrero de 2011.
} 
Por dicha ley se reconoció la autonomía académica y docente y la autarquía administrativa y económica, pero se prohibió terminantemente el proselitismo político partidario y determinaba la participación de docentes, estudiantes y no docentes en el gobierno de las universidades, estableciendo para la composición del gobierno de estas la Asamblea Universitaria, conformada por el Rector, los miembros del Consejo Superior y de los Consejos Directivos de cada Facultad. El gobierno tripartito eliminado en la ley 17245, vuelve en este punto al régimen de la ley 13031, y reaparece en 1974 en la ley $20654,{ }^{61}$ pero con dos particularidades distintivas: por un lado, en la fórmula no figuran los graduados sino los llamados "no-docentes" (es decir, el personal administrativo, técnico y de apoyo); y, por otro lado, se fija el peso relativo de cada representación, un $60 \%$ de docentes, un $30 \%$ de estudiantes y un $10 \%$ de no docentes. Los estudiantes peronistas sostenían que se había perdido medio año y se iba a malgastar el resto si docentes y estudiantes no se unían para evitar estos inconvenientes. ${ }^{62}$

Además dispuso que las designaciones de los rectores, vicerrectores y decanos "normalizadores", serían competencia del Poder Ejecutivo Nacional mientras que la elección de los decanos recaería en el rector, estableciéndose un plazo para instalar un gobierno autónomo en cada una de ellas, sin embargo, esto nunca llegó a cumplirse, ya que las pugnas internas del peronismo influían en dichos nombramientos que dependían del Ministerio de Educación.

La oposición, representada principalmente por el radicalismo, defendió, desde la tradición reformista la elección de las autoridades por medio de la Asamblea Universitaria. El conflicto fue dirimido por el mismo presidente de la República, quien dispuso que el nombramiento de sus miembros fuera definido por los estatutos de las universidades (art. 23 y 29). No obstante, se reservó para el Poder Ejecutivo la aprobación de estos, previa elevación de una propuesta por parte de la Asamblea Universitaria (art. 22). Para la designación de profesores y auxiliares docentes se previó la realización de concursos públicos de antecedentes y oposición; al respecto cada universidad nacional debía elaborar su propio Reglamento de acuerdo con la normativa de su Estatuto (art. 9). La injerencia de la universidad en el diseño de

61 Anales de Legislación Argentina, 1974, Tomo XXXIV-A (Buenos Aires: Editorial la Ley, 1974).

62 La Universidad de Córdoba tenía 30000 estudiantes que constituían el $5 \%$ de la población total de la ciudad. 
estrategias y acciones para la resolución de los problemas nacionales es otro de los aspectos vinculados a la dimensión política de la autonomía, en tanto ella es productora de saberes específicos.

"Las universidades nacionales son comunidades de trabajo que integran el sistema nacional de educación en el nivel superior con el fin de impartir enseñanza, realizar investigación, promover la cultura nacional, producir bienes y prestar servicios con proyección social, haciendo aportes necesarios y útiles al proceso de liberación nacional, contribuir a la solución de los grandes problemas argentinos" (art. $1^{\circ}$ )

Definía como funciones de las universidades una impronta del proyecto peronista "el capacitar profesionales y técnicos con conciencia argentina según los "requerimientos nacionales y regionales", formados para actuar "orientados hacia la felicidad del pueblo y a la grandeza de la Nación". Otra de las funciones sería estimular "los estudios sobre la realidad de la Argentina", con el objetivo de establecer "la independencia tecnológica y económica" (art. $2^{\circ}$ ).

El 12 de junio Perón, en su último discurso al pueblo argentino, manifestó que creía que había llegado la hora de reflexionar acerca de lo que pasaba en el país y depurar de malezas ese proceso porque, de lo contrario, podían esperarse horas muy aciagas para el porvenir de la República. En esa ocasión al hablar sobre la Universidad dijo:

La Universidad es foco de semejantes insensateces. Querían su ley, la tienen y está en plena organización normalizadora. ¿A qué seguir agitando un asunto terminado en lo sustancial? ¿Cómo se explica que ello suceda, solamente con fines extra universitarios? Esperamos los concursos para el profesorado. Será preciso asegurar que el resultado de ellos sea respetado y defendido por todos, como una garantía para que la Universidad, que valdrá tanto como sea el valor de su profesorado, pueda organizarse. ${ }^{63}$

En agosto de 1974 los problemas universitarios se agravarían en tanto Perón designó en reemplazo de Taiana como ministro de educación a Oscar Ivanissevich, un miembro de la derecha peronista. Poco tiempo después

63 Presidencia de la Nación, Mensaje de Juan Domingo Perón dirigido al pueblo argentino desde el salón Blanco de la casa de gobierno, 12 de junio, 1974. 
se pusieron en evidencia las incompatibilidades entre el proyecto del viejo caudillo y ese incierto "socialismo nacional" que sustentaban las juventudes radicalizadas.

El fallecimiento de Perón -acaecido el 1 de julio de 1974- abortaría este proyecto en poco tiempo. En definitiva, la vigencia de esta ley fue breve y tuvo escasa aplicación en ese contexto socio político convulsionado y confuso.

\section{CONCLUSIÓN}

Este rápido esbozo de una parte de la historia de la Universidad de Córdoba, que se inicia con los prolegómenos de la dictadura del general Juan Carlos Onganía y finaliza con la muerte de Juan Domingo Perón en 1974, acontecimiento que da paso a una democracia débil que abre el camino a otra oscura dictadura en 1976, permite arribar a algunas conclusiones.

En primer término, esta casa de altos estudios estuvo sometida a los vaivenes de la política nacional y local, en tanto el proceso político inaugurado en 1966 concibió a la institución como uno de los elementos claves para alcanzar los fines de su gestión. En dicho lapso, la dictadura organizó un plan centralizado destinado a depurar la Universidad de sus "componentes subversivos" y a la restauración de los valores religiosos y políticos occidentales. En cuanto a las relaciones Estado-Universidad terminaron con la autonomía que se convirtió en sí misma en un elemento de discusión constante entre los estudiantes que estaban ampliamente politizados, incluidas las mujeres. Las asambleas en el comedor estudiantil y las manifestaciones y "actos relámpagos" callejeros de protestas eran los lugares donde los militantes de las diferentes agrupaciones deponían o continuaban sus discusiones. En el interregno del gobierno peronista iniciado en 1973 se buscó en sus inicios subordinar la universidad al proyecto de emancipación nacional. Las luchas estudiantiles que se abrieron entonces fueron por quién hegemonizaba el poder dentro del peronismo. En segundo término, debemos reiterar que en el lapso de estudio hubo éxodo de profesores, se debilitó la investigación y la docencia pero aparecieron problemas nuevos: menores presupuestos, descenso de la matrícula, aumento de la deserción estudiantil y bajo promedio de egresos, problemas que hoy, pese a la estabilidad política, se mantienen, lo que exige a los que gobiernan estas casas de estudios la búsqueda de soluciones tendientes a lograr el nivel de excelencia que ella requiere. 


\section{FUENTES}

Archivo General de la Universidad de Córdoba [A.G.H.U.C.]

Actas del Honorable Consejo Superior. 19662 tomos.

Actas del Honorable Consejo Superior. 1966-7-1968, Tomo único.

Actas del Honorable Consejo Superior. 1970. Tomo 101

Actas del Honorable Consejo Superior. 1973. Tomo único

Resoluciones del H. Consejo Superior, Tomo único 1966-

Resoluciones de la intervención 1973. Tomo 1 y 2.

\section{Legislación}

Autor. Anales de Legislación Argentina, Tomo XXXIV-A- Buenos Aires: Editorial la Ley, 1974.

Departamento de Estadísticas, Anuario de Estadísticas Universitarias, UNC, 1961-1965

Ley 20654/74. Disponible: http: / / www.coneau.gov.ar/archivos/547.pdf. consultado 28 de febrero de 2011.

Argentina, Secretaría de estado de cultura y educación de la nación, “Ley Orgánica de las Universidades Nacionales 17245". Buenos Aires: promulgada el 21 de abril, 1967.

Presidencia de la Nación, Discurso de Perón desde la residencia de Olivos a los gremialistas cordobeses y a los jóvenes. Buenos Aires: Impreso en los Talleres Gráficos de la Dirección Nacional del Registro Oficial, 1974.

Revistas

Aquí y Ahora 1974-1975.

Cristianismo y Revolución 1966-1971. Edición digital completa de CEDINCI, 2 vol. Centro de Documentación en Investigaciones de la Cultura de Izquierda. Director de la revista Juan García Elorrio

Jerónimo, "Todo lo que pasó en el Cordobazo". 15 de junio de 1969. Año 1-N 11. Pag. 18-23. Revista de Córdoba dirigida por Miguel Angel Piccato.

Ayeres, Revista mensual de la ciudad de Córdoba, ano IX. El tomo titulado La Voz del Interior en la dictadura.

Estudios, Revista del Centro de Estudios Avanzados. Universidad Nacional de Córdoba, Córdoba, En papel y en Espacio virtual del Centro de Estudios Avanzados. http://revistas.unc. edu.ar/index.php/restudios/issue/archive

\section{Periódicos}

Diario Córdoba, 27 de mayo, 1990. A 21 años del Cordobazo .Edición Homenaje

La Prensa, marzo, 1976. Director Florencio Aldrey Iglesias

La Nación 1966- 1983. Director Bartolomé Mitre, taranieto del fundador del mismo nombre. La Voz del Interior, agosto de 1965 a 1983, 1999, junio 2010. Director Carlos Jornet.

Los Principios, periódico cordobés de tendencia católica. 1966-1970

Página12, 2010. Director desde 1994 Ernesto Tiffenberg. Fundado por Jorge Lanata. 


\section{REFERENCIAS}

AA.VV., I Jornadas de Historia de las izquierdas. Buenos Aires: 8 y 9 de diciembre, CEDINCI, 2000.

AA.VV. Universidad Nacional de Córdoba, Cuatrocientos años de historia, Tomo II. Córdoba: Imprenta de la Universidad, 2013.

AA.VV. Facultades de la UNC. 1854-2011. Saberes, procesos políticos e institucionales. Colección 400 años. Córdoba: 2013.

Agulla, Juan Carlos. Eclipse de una aristocracia. Una investigación sobre las elites dirigentes de la ciudad de Córdoba. Buenos Aires: Ediciones Libera, 1968.

Baronetto Luis, Rodeiro L, Vazquez G., Córdoba 1973. Escritos para Ricardo Obregón Cano. Córdoba: Editorial Facultad de Filosofía y Humanidades, 2012.

Bonavena, Pablo Augusto. "El movimiento estudiantil frente a la masacre en Trelew del 22 de agosto de 1972". Conflicto Social, Año 4, 5, (2011) Consultado 1 de setiembre de 2013. http: / / webiigg.sociales.uba.ar/conflictosocial/ revista

Bonavena, Pablo y Mariano Millán, "La lucha del movimiento estudiantil cordobés por el ingreso irrestricto a la Universidad en 1970 y 1971". En Estudios de la historia de Córdoba en el siglo XX. Gardenia Vidal, y Jessica Blanco, Córdoba: Ferreyra edit., 2010, 65 a 84.

Burgos Raúl, Los Gramscianos Argentinos: Cultura y politica en la experiencia de pasado y presente. Buenos Aires: Siglo XXI, 2004.

Delich Francisco, Crisis y protesta social, Córdoba, mayo de 1969. Buenos Aires. Signos 1970. Hay varias ediciones. Se utilizó la primera edición.

Donatello, Luis Miguel. "Religión y política: Las redes sociales del catolicismo post-conciliar y los Montoneros, 1966-1973", Revista Estudios Sociales 24, UNL, (2003): 89 a 111.

Donatello, Luis Miguel. Catolicismo y Montoneros: Religión, política y desencanto. Buenos Aires: Manantial, 2010.

González, Marcela. Una historia con sentido. Los primeros 50 años de la Universidad Católica de Córdoba, 1956-2006. Córdoba: Editorial de la UCCC, 2006.

Gordillo, Mónica. "Los prolegómenos del Cordobazo. Los sindicatos líderes de Córdoba dentro de la estructura del poder sindical". Desarrollo Económico, Revista de Ciencias Sociales, Vol. 31, 122(1991): 111-135

Kaufmann, Carolina. Dictadura y Educación. Tomo 1. Universidad y grupos académicos argentinos (1976-1983). Buenos Aires: Miño y Dávila, 2001.

Lanusse Lucas. "La Universidad Montonera. Agrupaciones Estudiantiles Católicas en Córdoba y Santa Fe y El Origen de Montoneros" Consultado 20 de julio de 2013 rapes.unsl.edu. ar/Congresos_realizados/Congresos/...\%200ct.../32.htm. 
Mendonça, Mariana. "Políticas de estado, segregación espacial, y creación de universidades nacionales en los años setenta. El caso de la Universidad Nacional de Río Cuarto". Consultado 20 de setiembre de 2013 www.mov-estudiantil.com.ar/terceras/2siete.doc.

Pedrosa, Fernando. "La Universidad y los estudiantes frente a la dictadura militar". En Movimientos estudiantiles en la historia de América Latina, II, coordinado por Renate Marsiske, 230 (México: Plaza Valdés, 1969).

Ponza, Pablo. Intelectuales y violencia política, 1955-1973. Córdoba: Babel Editorial, 2010.

Ruiz, Guillermo y Nancy Cardinaux (Comp.). La autonomía universitaria: Definiciones Normativas y Jurisprudenciales en clave histórica y actual. Buenos Aires: Editorial La Ley S.A., 2010.

Sánchez Martínez, Eduardo. La legislación sobre la educación superior en Argentina. Entre rupturas, continuidades y transformaciones. Buenos Aires: Universidad de Belgrano, 2003. Consultado 20 de seteimbre de 2013. http:/ / www.ub.edu.ar/investigaciones/dt_nuevos/102_ sanchez_martinez.pdf

Tcach, César (Coord.). Córdoba Bicentenaria. Claves de su historia contemporánea. Córdoba: CEA UNC, 2010.

Teran, Oscar. “Ideas e intelectuales en la Argentina, 1880-1980". En Oscar Terán [Coord.] Ideas en el siglo. Intelectuales y cultura en el siglo XX latinoamericano (Buenos Aires: Siglo veintiuno editores, 2004, 13 a 92.

Torre, Juan Carlos. "A partir del Cordobazo". Estudios (Córdoba) 4, (julio-diciembre, 1994): 65.

Urondo, Francisco. Trelew. La patria fusilada. Buenos Aires: Editorial Contrapunto, 1988.

Vera de Flachs, María Cristina. "Notas para la Historia de la Universidad Argentina." Revista Historia de la Educación Latinoamericana 8 (2006): 65-112.

Vera de Flachs, María Cristina, “Escarceos estudiantiles en época de dictadura. Argentina 1976-1981". Movimiento estudiantiles, R. Marsiske, México: UNAM, 2013. En prensa.

Villar, Daniel. El Cordobazo. Buenos Aires: Centro Editor de América Latina, Talleres Gráficos de Sebastián de Amorrurtu e Hijos, S.A., 1971.

Vera de Flachs, María Cristina. "Universidad, dictadura y movimientos estudiantiles en Argentina. Córdoba 1966-1974”. Revista Historia de la Educación Latinoamericana. Vol. 15 No, 21, (2013): 191 - 228. 